\title{
How much abdominal fat do obese patients lose short term after laparoscopic sleeve gastrectomy? A quantitative study evaluated with MRI
}

\author{
Jing Sun ${ }^{1 \#}$, Han $\mathrm{Lv}^{1 \#}$, Mengyi $\mathrm{Li}^{2}$, Lei Zhao ${ }^{1}$, Yawen $\mathrm{Liu}^{3}$, Na Zeng ${ }^{4}$, Xuan Wei ${ }^{1}$, Qian Chen ${ }^{1}$, Pengling Ren ${ }^{1}$, \\ Yang Liu ${ }^{2}$, Peng Zhang ${ }^{2}$, Zhenghan Yang ${ }^{1}$, Zhongtao Zhang ${ }^{2}$, Zhenchang Wang ${ }^{1}$ \\ ${ }^{1}$ Department of Radiology, Beijing Friendship Hospital, Capital Medical University, Beijing, China; ${ }^{2}$ Department of General Surgery, Beijing \\ Friendship Hospital, Capital Medical University \& National Clinical Research Center for Digestive Diseases, Beijing, China; ${ }^{3}$ School of Biological \\ Science and Medical Engineering, Beihang University, Beijing, China; ${ }^{4}$ National Clinical Research Center for Digestive Diseases, Beijing Friendship \\ Hospital, Capital Medical University, Beijing, China
}

Contributions: (I) Conception and design: J Sun, H Lv; (II) Administrative support: P Zhang, Z Yang, Z Zhang, Z Wang; (III) Provision of study materials or patients: M Li, Y Liu, P Zhang, Z Zhang; (IV) Collection and assembly of data: J Sun, H Lv, L Zhao, Y Liu, X Wei, Q Chen, P Ren; (V) Data analysis and interpretation: J Sun, H Lv, M Li, Y Liu, N Zeng; (VI) Manuscript writing: All authors; (VII) Final approval of manuscript: All authors.

\#These authors contributed equally to this work.

Correspondence to: Zhongtao Zhang. Department of General Surgery, Beijing Friendship Hospital, Capital Medical University \& National Clinical Research Center for Digestive Diseases, No.95, Yong An Road, Xicheng District, Beijing 100050, China. Email: zhangzht@ccmu.edu.cn; Zhenchang Wang. Department of Radiology, Beijing Friendship Hospital, Capital Medical University, No.95, Yong An Road, Xicheng District, Beijing 100050, China. Email: cjr.wzhch@vip.163.com.

Background: This study aimed to elucidate the changes in the amount of abdominal adipose tissue after laparoscopic sleeve gastrectomy in obese Chinese patients over a relatively short follow-up period and to analyze the differences in the effects of surgery between genders.

Methods: Ninety-one patients were enrolled in the study, including 18 males and 73 females. These patients underwent laparoscopic sleeve gastrectomy between November 2017 and November 2019. Before and short term after surgery, the areas of subcutaneous/visceral adipose tissue and the liver proton density fat fraction were calculated with upper abdominal magnetic resonance (MR) examinations.

Results: Approximately 100 days after surgery, the median values of weight loss and body mass index reduction were $23.1 \mathrm{~kg}$ and $8.1 \mathrm{~kg} / \mathrm{m}^{2}$, respectively. The patients achieved a greater absolute loss of subcutaneous adipose tissue index than of visceral adipose tissue index $\left(3.2 \times 10^{-3} v\right.$ s. $\left.1.6 \times 10^{-3}, \mathrm{P}<0.001\right)$. The amount of weight loss, body mass index loss and absolute/relative reduction in visceral adipose tissue index were much greater in males than in females $\left(31.7\right.$ vs. $21.7 \mathrm{~kg}, \mathrm{P}<0.001 ; 9.8$ vs. $7.9 \mathrm{~kg} / \mathrm{m}^{2}, \mathrm{P}=0.016 ; 2.5 \times 10^{-3}$ vs. $1.3 \times 10^{-3}, \mathrm{P}=0.007 ; 28.2 \%$ vs. $\left.20.9 \%, \mathrm{P}=0.029\right)$. There was a correlation between decreased amounts in subcutaneous and visceral adipose tissue in sum and weight loss $(\mathrm{r}=0.282, \mathrm{P}=0.032)$. The absolute/relative reduction in visceral adipose tissue index was also correlated with absolute/relative reduction in liver proton density fat fraction ( $r=0.283, \mathrm{P}=0.013 ; \mathrm{r}=0.372, \mathrm{P}=0.001)$.

Conclusions: The reductions in body weight and visceral fat were more significant in male patients. The sum of absolute reduction in subcutaneous and visceral fat deposits was correlated with weight loss, in all patients enrolled. For severely obese patients, an upper abdominal MR examination could assess the body tissue composition and how it changes after bariatric surgery. 
Keywords: Upper abdominal magnetic resonance imaging (upper abdominal MRI); single magnetic resonance slice (single MR slice); bariatric surgery; abdominal adipose tissue

Submitted Dec 21, 2020. Accepted for publication May 28, 2021.

doi: $10.21037 /$ qims-20-1380

View this article at: https://dx.doi.org/10.21037/qims-20-1380

\section{Introduction}

The worldwide incidence of obesity has been increasing at a drastic rate in recent years (1). It is estimated that the prevalence of obesity will increase by $33 \%$ in the next 20 years (1). Bariatric surgery, especially laparoscopic sleeve gastrectomy (LSG), is among several treatment strategies used for managing obesity. Further, LSG is the mainstream surgical procedure practiced worldwide and has proven to be efficient in reducing adiposity and body weight and improving metabolic abnormalities in severely obese patients (2-10).

The distribution of excess body fat, specifically visceral adipose tissue (VAT), is strongly correlated with diverse metabolic disorders and cardiovascular diseases $(8,11,12)$. The decline in subcutaneous adipose tissue (SAT) was markedly different from the decline in VAT after bariatric surgery. Recently, Kengott et al. (7) used whole-body magnetic resonance imaging (MRI) to analyze individual changes in the SAT and VAT compartments after bariatric surgery. After 1 year, the patients showed a larger relative decrease in VAT than in SAT, while the opposite was true of the absolute decrease. The patients enrolled in the study were Caucasian. It has been established that there are differences in body tissue composition and changes $(13,14)$ and differences in the degree and type of obesity between ethnicities (15). Thus, the results from a Caucasian sample cannot be directly applied to Chinese people undergoing similar surgical procedures.

Follow-up at three months after the operation has always been a common practice in the Department of Bariatric and Metabolic Surgery in Beijing Friendship Hospital. At this time, the patients with obesity showed a significant reduction in abdominal fat, which can be observed physically. The abdominal fat consists of SAT, VAT, and fat within organs, among which hepatic fat content is the main indicator of fat content within organs. Thus, we attempted to quantify the changes in SAT, VAT, and hepatic fat content three months after surgery. The liver Proton Density Fat Fraction (PDFF) image acquired from MRI has been confirmed as an accepted alternative to liver biopsy for the accurate estimation of hepatic fat content $(16,17)$. The Liver Accumulation with Volume Acceleration-flexible (LAVA-Flex) sequence of MRI has been shown to be the optimal choice for displaying and quantifying SAT and VAT (18).

The objective of this study was to investigate the changes in postoperative visceral and subcutaneous fat and intrahepatic fat deposits in obese Chinese patients over a short follow-up period using the Greater China Metabolic and Bariatric Surgery Database (GC-MBD) launched by our institution. We also assessed whether the gender of the patient would influence postoperative changes. In addition, we aimed to elucidate how changes in the three types of abdominal fat were correlated with each other and how changes in abdominal fat were associated with weight loss, thus assisting in patient management and evaluation of surgical outcomes.

\section{Methods}

\section{Subjects}

Beijing Friendship Hospital is one of the largest-volume centers for bariatric and metabolic surgery in China, and LSG is the main surgical procedure adopted. As a retrospective study, we reviewed all patients who underwent LSG surgery at our institution between November 2017 and November 2019. The indications for bariatric surgery were those who met the World Health Organization (WHO) criteria for morbid obesity in Asian populations, according to the international operation standards (15). Patients aged 18 years or older with a definite diagnosis of morbid obesity were included. The patient anthropometric data needed was extracted from the GC-MBD, ClinicalTrials. gov was NCT 03800160 .

The inclusion criteria for this study were as follows: (I) patients were undergoing LSG surgery for the first time; (II) patients underwent upper abdominal MR examination before and short-term after the operation; (III) the precise time interval between the first and second MR scans was 


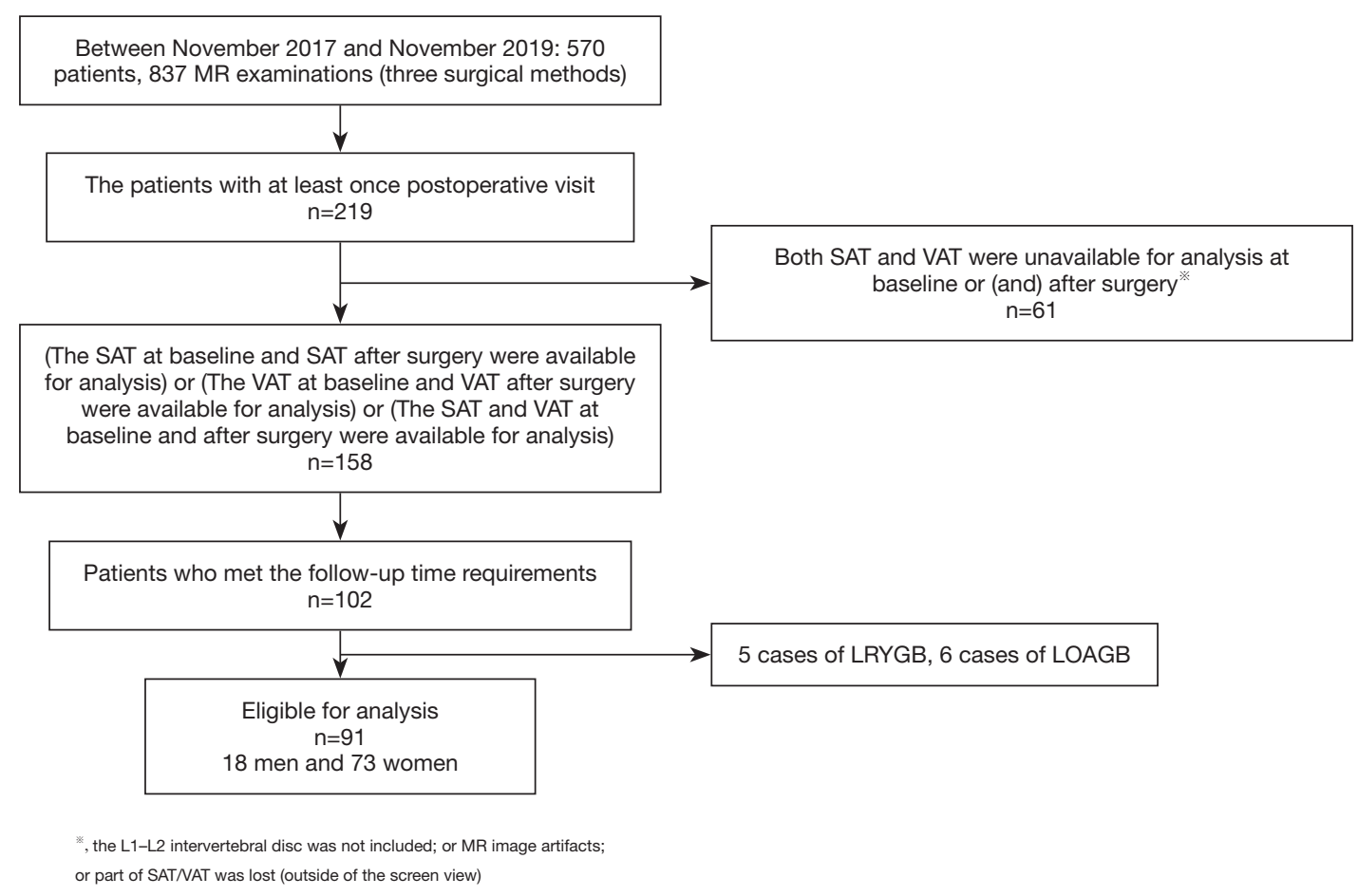

Figure 1 Patient selection for eligible subjects. SAT, subcutaneous adipose tissue; VAT, visceral adipose tissue; LRYGB, Laparoscopic Rouxen-Y gastric bypass; LOAGB, Laparoscopic one-anastomosis gastric bypass; L, lumbar.

$100 \pm 30$ days; (IV) both the preoperative and postoperative MR scans included the axial level of lumbar 1 and 2 (L1L2) intervertebral disc; and (V) there were MR sequences on which the liver PDFF and SAT/VAT could be quantified accurately.

This study excluded: (I) patients with anastomotic fistula, obstruction, stenosis, and other surgical complications who were unable to carry out physiological digestion and metabolism; (II) patients who underwent revisional surgery during the follow-up period; (III) MR image artifacts or part of SAT/VAT was lost (outside of the screen view) which restricted measurements; and (VI) patients with MR contraindications such as claustrophobia, heart pacemakers, stents, and metal implants. Of note, patients with missing preoperative or postoperative weight data were excluded when analyzing the correlation between abdominal fat changes and weight loss.

A total of 91 patients who underwent LSG and met the requirements were enrolled in our study, comprising 18 males and 73 females (Figure 1). The minimum MR scan interval was $86 \mathrm{~d}$, and the maximum was $130 \mathrm{~d}$. The median value and interquartile range of the time interval were presented as $100 \mathrm{~d}(96-108 \mathrm{~d})$.

\section{MR image acquisition}

The upper abdominal MR images were acquired at the Department of Radiology using an MRI scanner (Discovery 3.0 T, 750 W, General Electric (GE) Medical Systems, Milwaukee, WI, USA). The participants were instructed to stay still throughout the scan and hold their breath when asked during the scanning process.

Each MR scan spanned from the top of the liver to the hilum of the kidney. An eight-channel phased-array abdominal coil was applied. The sequences of Liver Acquisition with Volume Acceleration-flexible (LAVA-Flex) were collected for quantification of SAT/VAT $(\mathrm{TR}=4.1 \mathrm{~ms}$; $\mathrm{TE}=1.9 \mathrm{~ms} ; \mathrm{FOV}=40 \mathrm{~cm} \times 32 \mathrm{~cm}$; slice thickness $=4 \mathrm{~mm}$; matrix $=160 \times 160$; flip angle $=12^{\circ} ; \mathrm{NEX}=1$; acquisition time $=15 \mathrm{~s}$ ).

In order to calculate liver PDFF, the sequences for the iterative decomposition of water and fat with echo asymmetry and the least-square estimation quantification (IDEAL IQ) were determined $(\mathrm{TR}=7.3 \mathrm{~ms}$; $\mathrm{TE}=\operatorname{six}$ different echo times between 1.0 and $5.0 \mathrm{~ms} ; \mathrm{FOV}=40$ $\mathrm{cm} \times 40 \mathrm{~cm}$; slice thickness $=8 \mathrm{~mm}$; matrix $=160 \times 160$; flip angle $=4^{\circ} ; \mathrm{NEX}=0.5$; acquisition time $=17 \mathrm{~s}$ ). 

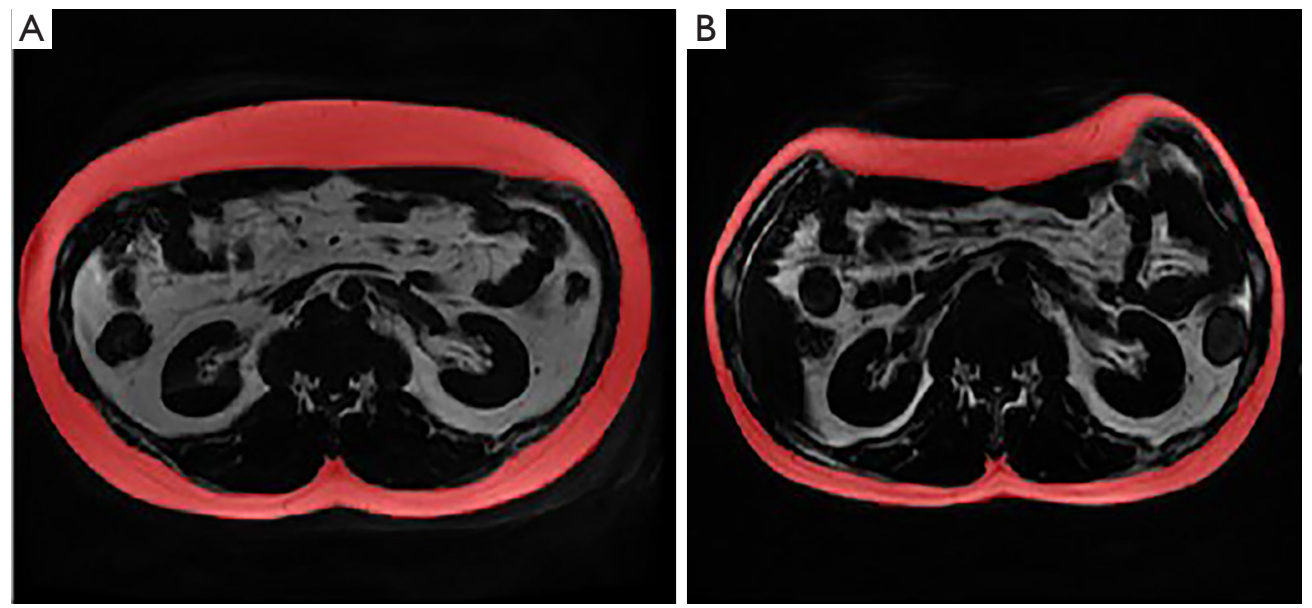

Figure 2 Outline of SAT area at the L1-L2 intervertebral disc on the LAVA-Flex sequence. (A) SAT in a male patient at baseline; (B) SAT at 113 days after LSG. The SATI at L1-L2 decreased from $7.7 \times 10^{-3}$ to $3.4 \times 10^{-3}$. SAT, subcutaneous adipose tissue; SATI, subcutaneous adipose tissue index; LSG, laparoscopic sleeve gastrectomy; L, lumbar.
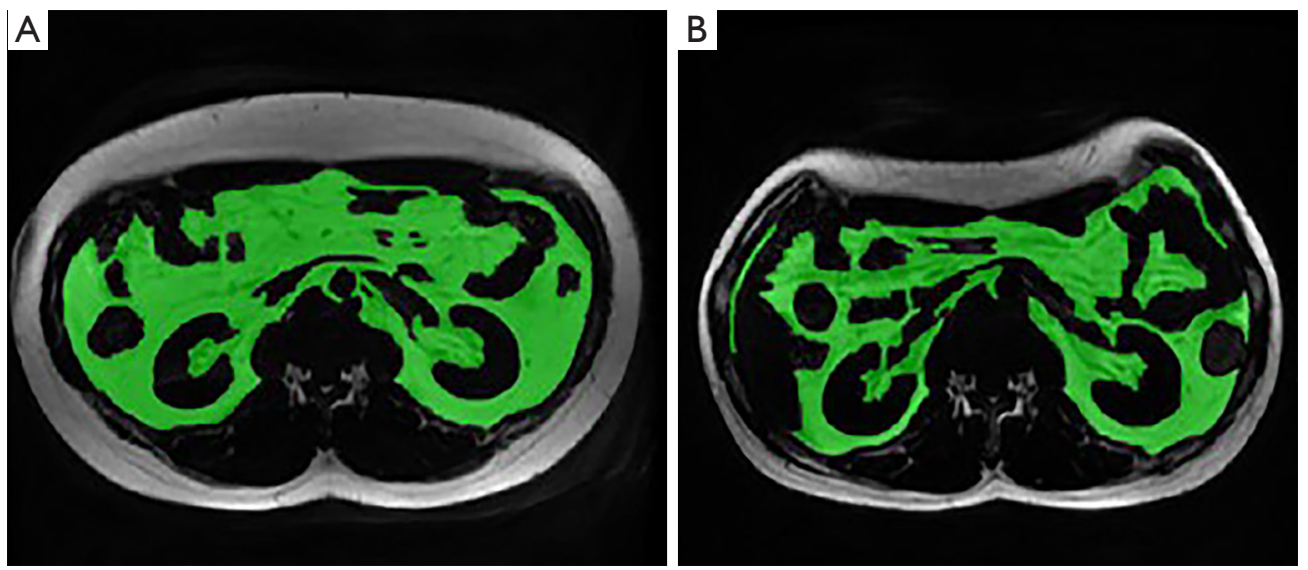

Figure 3 Outline of VAT area at the L1-L2 intervertebral disc on the LAVA-Flex sequence. (A) VAT in the same male patient at baseline; (B) VAT at 113 days after LSG. The VATI at L1-L2 decreased from $7.7 \times 10^{-3}$ to $4.9 \times 10^{-3}$. VAT, visceral adipose tissue; VATI, visceral adipose tissue index; LSG, laparoscopic sleeve gastrectomy; L, lumbar.

\section{MRI image processing}

The RadiAnt DICOM Viewer software (version 2020.2) was used to read the collected LAVA-Flex images. First, two experienced radiologists manually identified the level of L1-L2 intervertebral disc on the RadiAnt based on the prescan positioning image and abdominal anatomical markers (e.g., the level of L1-L2 approximately equals the level of the kidney hilum). Then, the L1-L2 slices were exported and collected through the image export function of RadiAnt (Figures 2,3).

The collected single slices of L1-L2 were imported into a medical image-processing software (ITK-SNAP version 3.8.0). Six trained radiologists with 5 years of diagnostic experience delineated the edge of SAT and VAT on ITKSNAP and acquired their volumes. The SAT and VAT was grouped according to the margin of musculi abdominis and paravertebral muscles. The measurement of VAT avoids the internal organs. The L1-L2 SAT, and VAT voxels and volumes were then recorded. The intraclass correlation coefficient (ICC) for the measurement of SAT and VAT between radiologists was 0.998 and 0.989 , respectively (both $\mathrm{P}<0.001)$. 

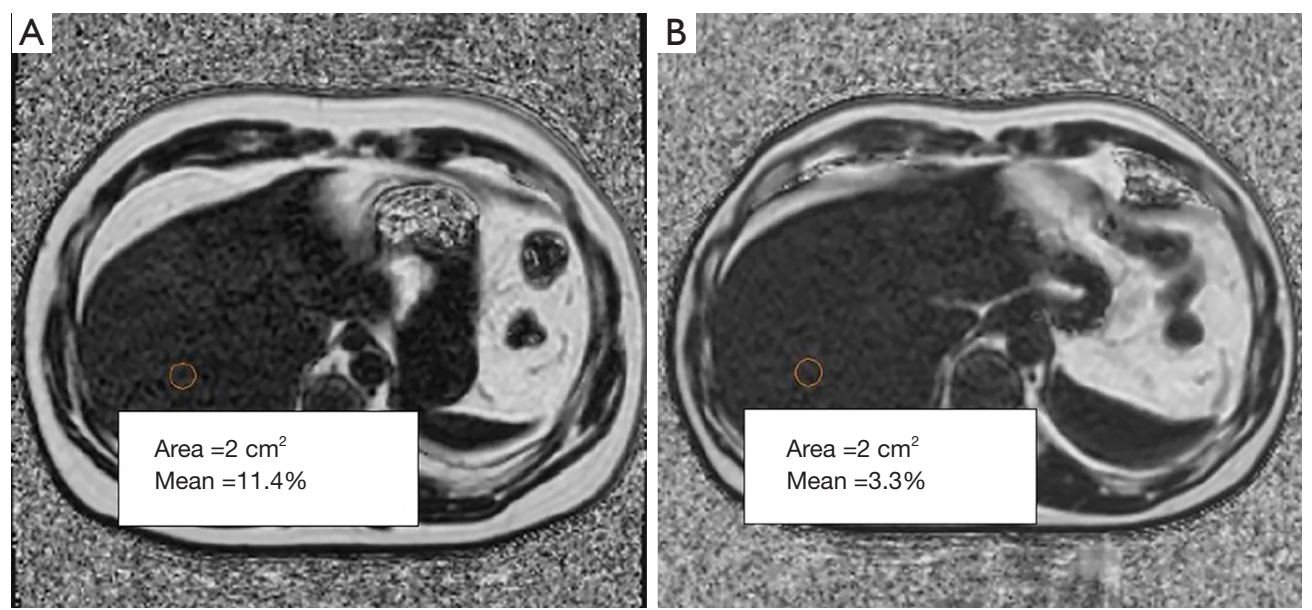

Figure 4 The acquisition of liver PDFF value on the PDFF map. (A) Liver PDFF in the same male patient at baseline; (B) liver PDFF at 113 days after LSG. The liver PDFF decreased from $11.4 \%$ to $3.3 \%$. PDFF, proton density fat fraction; LSG, laparoscopic sleeve gastrectomy.

The IDEAL IQ sequence patient images were transferred to a GE Advantage Workstation (ADW4.6) to obtain PDFF maps. On the PDFF maps, two radiologists with 5 years of experience then outlined eight-round regions of interest (ROIs) representing hepatic segments I-VIII correspondingly. The area of each ROI was set to $2 \mathrm{~cm}^{2}$ in the center of the segment, avoiding the hepatic fissures and blood vessels (Figure 4). The PDFF value for each liver segment was calculated twice. In the last step, the mean of eight PDFF values from the corresponding eight liver segments was recorded as the final individual liver PDFF result (\%). The intraclass correlation coefficient (ICC) for the measurement of liver PDFF between radiologists was $0.991(\mathrm{P}<0.001)$.

\section{Data processing}

MR images were taken in $4 \mathrm{~mm}$ slices. The results we initially measured with ITK-SNAP were the volume of SAT and VAT found at the level of L1-L2 intervertebral disc. Thus, in order to eliminate the influence of slice thickness, we used a conversion formula to convert the SAT/VAT volume $\left(\mathrm{mm}^{3}\right)$ into the SAT/VAT area $\left(\mathrm{mm}^{2}\right)$ in the slice.
The conversion formula was:

$$
\text { area }=\text { voxel count } \times \text { pixel spacing }(x) \times \text { pixel spacing }(y)
$$

Then, the SAT and VAT area was adjusted for height squared $\left(\times 10^{-6}\right)$, which was subcutaneous adipose tissue index (SATI) and visceral adipose tissue index (VATI) respectively. This calculation method has been described previously (19). The SATI $\left(\times 10^{-6}\right)$ was calculated as:

$$
\operatorname{SATI}\left(\times 10^{-6}\right)=\frac{\text { SAT area }}{\text { height }^{2}}
$$

The VATI $\left(\times 10^{-6}\right)$ was calculated as:

$$
\operatorname{VATI}\left(\times 10^{-6}\right)=\frac{\text { VAT area }}{\text { height }^{2}}
$$

The magnitude of adipose tissue (AT) at baseline determines the loss of AT with weight loss. Therefore, we calculated the relative change (reduction rate, \%) to eliminate the effect of baseline values. To make the reduction degrees in these three types of fat comparable, we also calculated the relative change of liver PDFF. The liver PDFF relative change (\%) was calculated as:

$$
\text { Liver PDFF relativechange }(\%)=\frac{\text { preoperativeliver } P D F F-\text { postoperativeliver PDFF at } 3 \text { months }}{\text { preoperativeliver } P D F F}(\%)
$$


The SATI (\%) was calculated as:

$$
\operatorname{SATI}(\%)=\frac{\text { preoperative SATI }- \text { postoperative SATI at } 3 \text { months }}{\text { preoperative SATI }}(\%)
$$

The VATI (\%) was calculated as:

$$
\operatorname{VATI}(\%)=\frac{\text { preoperativeVATI }- \text { postoperativeVATI at } 3 \text { months }}{\text { preoperativeVATI }}(\%)
$$

Total weight loss (\% TWL), excess weight loss (\%EWL), and excess weight were commonly used at the Bariatric and Metabolic Surgery Department to evaluate weight changes. \% TWL was calculated as:

$$
\% T W L=\frac{\text { preoperative weight }- \text { postoperative weight at } 3 \text { months }}{\text { preoperative weight }}(\%)
$$

\%EWL was calculated as:

$$
\% E W L=\frac{\text { preoperative weight }- \text { postoperative weight at } 3 \text { months }}{\text { excess weight }}(\%)
$$

The body mass index (BMI) was calculated as:

$$
B M I=\frac{\text { body weight }}{\text { body height }^{2}}
$$

\section{Statistical analysis}

The statistical analysis was performed by IBM SPSS Statistics 25. The Kolmogorov-Smirnov test was applied to determine the normal distribution of the data from each group. The postoperative changes in all the patients were compared using the Kruskal-Wallis test, and then the Bonferroni correction was used for pairwise comparisons. The effects of bariatric surgery between genders were compared with the Mann-Whitney $\mathrm{U}$ test and independentsamples $t$-test. The multivariate linear regression analysis was then used to determine whether the baseline values affected the statistical results. The Pearson rank correlation and the Spearman rank correlation were used to assess the correlation among three parts of abdominal fat reduction and the correlation between abdominal fat reduction and weight loss. The normally distributed data were presented as mean \pm standard deviation (SD). The data with a skewed distribution were presented as median (the lower quartile, the upper quartile). $\mathrm{P}$ value $<0.05$ (two-tailed) was considered to be statistically significant.

The study was conducted following the Declaration of Helsinki (as revised in 2013). The study was approved by the Medical Ethics Committee of Beijing Friendship

Hospital (No. 2017-P2-131-02) and individual consent for this retrospective analysis was waived.

\section{Results}

The postoperative weight, BMI, liver PDFF, SATI, and VATI were all significantly decreased from the baseline values (Table 1). The median values of weight loss and BMI reduction were 23.1 and $8.1 \mathrm{~kg} / \mathrm{m}^{2}$, respectively. The absolute loss of SATI was observed to be greater than that of VATI $\left(3.2 \times 10^{-3}\right.$ vs. $\left.1.6 \times 10^{-3}, \mathrm{P}<0.001\right)$. There was no significant difference between the relative change in SATI and VATI (25.4\% vs. $22.3 \%, \mathrm{P}=0.706)$, but the relative change in liver PDFF was markedly larger than the change in SATI $(62.1 \%$ vs. $25.4 \%, \mathrm{P}<0.001)$ and VATI $(62.1 \%$ vs. $22.3 \%, \mathrm{P}<0.001)$. The results were displayed in Figure 5 .

\section{Analysis of differences by gender}

The males had higher reductions in weight and BMI and higher absolute/relative VATI changes, and lower EWL than females. However, for TWL and absolute/relative liver PDFF/SATI change, males and females showed no difference (Table 1).

By multivariate linear regression analysis, the influence of gender on weight loss and BMI loss showed no statistical significance $(\mathrm{P}=0.555 ; \mathrm{P}=0.958)$. The influence of baseline weight on weight loss between men and women was statistically significant $(\beta=0.689, \mathrm{P}<0.001)$. The influence of 
Table 1 The parameter values at baseline and short-term after surgery

\begin{tabular}{|c|c|c|c|c|}
\hline Characteristic & Baseline & Short-term follow-up & Change & $P$ value \\
\hline Males & $141.8 \pm 20.4$ & $110.1 \pm 16.5$ & $31.7 \pm 7.9$ & $<0.001^{b}$ \\
\hline Females & $99.2(90.3,115.9)$ & $81.9 \pm 15.9$ & $21.7(17.2,25.5)$ & \\
\hline EWL (\%) & & & $58.7(48.7,81.3)$ & N/A \\
\hline Females & - & - & $61.8(50.3,83.8)$ & \\
\hline TWL (\%) & & & $20.6(18.3,23.5)$ & $\mathrm{N} / \mathrm{A}$ \\
\hline Males & - & - & $22.3 \pm 4.1$ & $0.313^{\mathrm{b}}$ \\
\hline Females & - & - & $20.5(18.1,23.4)$ & \\
\hline Females & $37.0(33.9,42.6)$ & $30.2 \pm 5.4$ & $7.9(6.5,9.4)$ & \\
\hline Liver PDFF (\%) & $13.60(7.79,20.34)$ & $3.44(2.44,6.60)$ & $6.74(3.74,14.42)$ & $<0.001^{\mathrm{a}}$ \\
\hline Males & $16.49 \pm 8.52$ & $3.31(2.28,6.68)$ & $11.39 \pm 7.75$ & $0.193^{b}$ \\
\hline Females & $14.02 \pm 8.63$ & $3.47(2.46,6.65)$ & $6.13(2.87,14.06)$ & \\
\hline Liver PDFF relative (\%) & & & $62.1(36.4,75.8)$ & N/A \\
\hline Males & - & - & $63.7 \pm 20.6$ & $0.352^{\mathrm{b}}$ \\
\hline Females & - & - & $59.3(30.3,76.0)$ & \\
\hline SATI $\left(\times 10^{-3}\right)$ & $12.6(9.3,15.8)$ & $9.6 \pm 3.6$ & $3.2(2.0,4.3)$ & $<0.001^{a}$ \\
\hline VATI $\left(\times 10^{-3}\right)$ & $6.9 \pm 2.1$ & $5.3 \pm 1.8$ & $1.6(0.8,2.0)$ & $<0.001^{a}$ \\
\hline Males & $8.5 \pm 2.5$ & $6.1 \pm 2.0$ & $2.5 \pm 1.5$ & $0.007^{b}$ \\
\hline Females & $6.5 \pm 1.9$ & $5.1 \pm 1.7$ & $1.3 \pm 0.8$ & \\
\hline VATI (\%) & & & $22.3 \pm 11.9$ & N/A \\
\hline Males & - & - & $28.2 \pm 15.9$ & $0.029^{b}$ \\
\hline Females & - & - & $20.9 \pm 10.4$ & \\
\hline
\end{tabular}

${ }^{a}$, weight/BMI/liver PDFF/SATI/VATI at baseline vs. approximately 100 days after surgery. ${ }^{\mathrm{b}}$, change in weight/BMI/liver PDFF/SATI/VATI and EWL/TWL/liver PDFF relative/SATI(\%)/VATI(\%) in males vs. in females. $\mathrm{P}<0.05$ (two-tailed) was considered to be statistically significant. EWL, excess weight loss; TWL, total weight loss; BMI, body mass index; PDFF, proton density fat fraction; SATI, subcutaneous adipose tissue index; VATI, visceral adipose tissue index. 


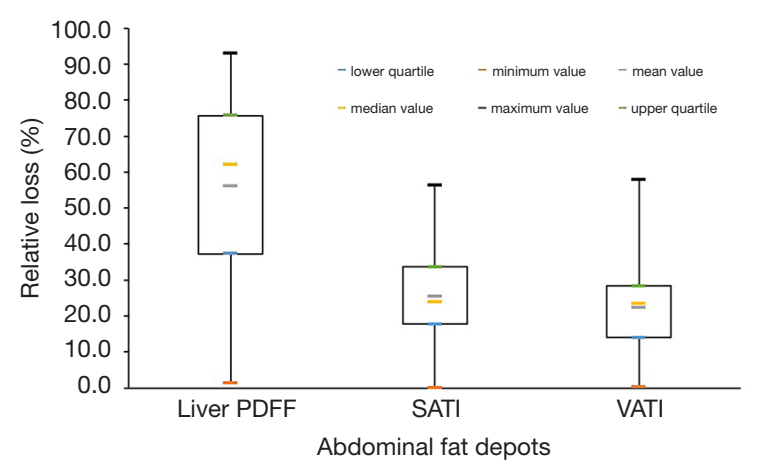

Figure 5 Pairwise comparison of relative loss among three different types of adipose tissue. The relative reduction in liver PDFF was higher than that of SATI $(\mathrm{P}<0.001)$ and VATI $(\mathrm{P}<0.001)$. There was no difference between the relative change in SATI and VATI ( $\mathrm{P}=0.706$, after Bonferroni correction). PDFF, proton density fat fraction; SATI, subcutaneous adipose tissue index; VATI, visceral adipose tissue index.

baseline BMI on BMI loss between males and females was also statistically significant $(\beta=0.563, \mathrm{P}<0.001)$. Both the gender and baseline VATI had a statistically significant influence on VATI reduction ( $\beta=-0.249, \mathrm{P}=0.007 ; \beta=0.479, \mathrm{P}<0.001)$.

\section{Correlation analysis among changes in different types of abdominal fat}

The correlation between the absolute reduction in VATI and absolute reduction in liver PDFF was statistically significant $(r=0.283, P=0.013)$. However, there was no correlation either between absolute reduction in SATI and absolute reduction in liver PDFF $(\mathrm{P}=0.162)$ or between absolute reduction in SATI and absolute reduction in VATI $(\mathrm{P}=0.912)$.

The correlation between the relative reduction in VATI and relative reduction in liver PDFF was statistically significant $(\mathrm{r}=0.372, \mathrm{P}=0.001)$. Additionally, the relative reduction in SATI was found to be correlated with relative reduction in VATI statistically $(\mathrm{r}=0.245, \mathrm{P}=0.049)$. No statistical correlation was found between relative reduction in SATI and relative reduction in liver PDFF $(\mathrm{P}=0.267)$.

Linear plots showing the Pearson and Spearman rank correlation results and the correlation coefficients were provided in Figure 6.

\section{Correlation analysis between abdominal fat reduction and changes in weight-related parameters}

A correlation was found between the absolute VATI reduction and weight loss $(\mathrm{r}=0.282, \mathrm{P}=0.011)$, while the absolute SATI reduction was not correlated with weight loss $(\mathrm{P}=0.214)$. The correlation between the absolute reduction in SATI + VATI and weight loss was statistically significant $(\mathrm{r}=0.282, \mathrm{P}=0.032)$. The relative reduction of VATI was also associated with TWL and EWL $(r=0.252, \mathrm{P}=0.022$; $\mathrm{r}=0.274, \mathrm{P}=0.013)$. Nevertheless, there was no correlation either between absolute liver PDFF reduction and weight loss $(\mathrm{P}=0.083)$ or between relative liver $\mathrm{PDFF}$ reduction and $\mathrm{EWL} / \mathrm{TWL}(\mathrm{P}=0.217 ; \mathrm{P}=0.052)$. The relative SATI reduction was not correlated with either EWL $(\mathrm{P}=0.051)$ or TWL $(\mathrm{P}=0.251)$.

Linear plots showing the Spearman rank correlation results and the correlation coefficients were provided in Figure 7.

\section{Discussion}

According to the GC-MBD 2019 Annual Report, the annual number of bariatric surgeries performed in China was roughly 10,000, while the obese population in China was estimated to be more than 100 million. Although the amount of bariatric surgery has increased significantly in China, large-scale clinical and longitudinal studies on the postoperative changes in body fat composition are still lacking. Moreover, abdominal obesity is more common among obese people in Asia (15). Abdominal obesity significantly increases the risks of metabolic syndrome and cardiovascular diseases (20). Therefore, this study aimed to investigate the changes in abdominal fat composition after surgery in a Chinese population and the inter-correlation among its three compartments.

Approximately three months after surgery, the median values of EWL and TWL were $58.7 \%$ and $20.6 \%$, respectively. For abdominal fat, the absolute reduction in SATI was much higher than that in VATI, while liver PDFF had the highest relative reduction among the three types of fat deposits. This may indicate that intrahepatic fat was more sensitive to changes in lipometabolism function. We can reasonably assume that improvement in bodily metabolic status may be partly reflected in liver PDFF changes.

The median weight before surgery in male patients was $140.0 \mathrm{~kg}$, and the median weight in female patients was $99.2 \mathrm{~kg}$. The average BMI at baseline for men was also far higher than that for women $\left(43.9 v s .37 .0 \mathrm{~kg} / \mathrm{m}^{2}\right)$. According to multivariate linear regression analysis, the higher body weight and BMI at baseline, rather than gender alone, explained why there were greater weight loss 

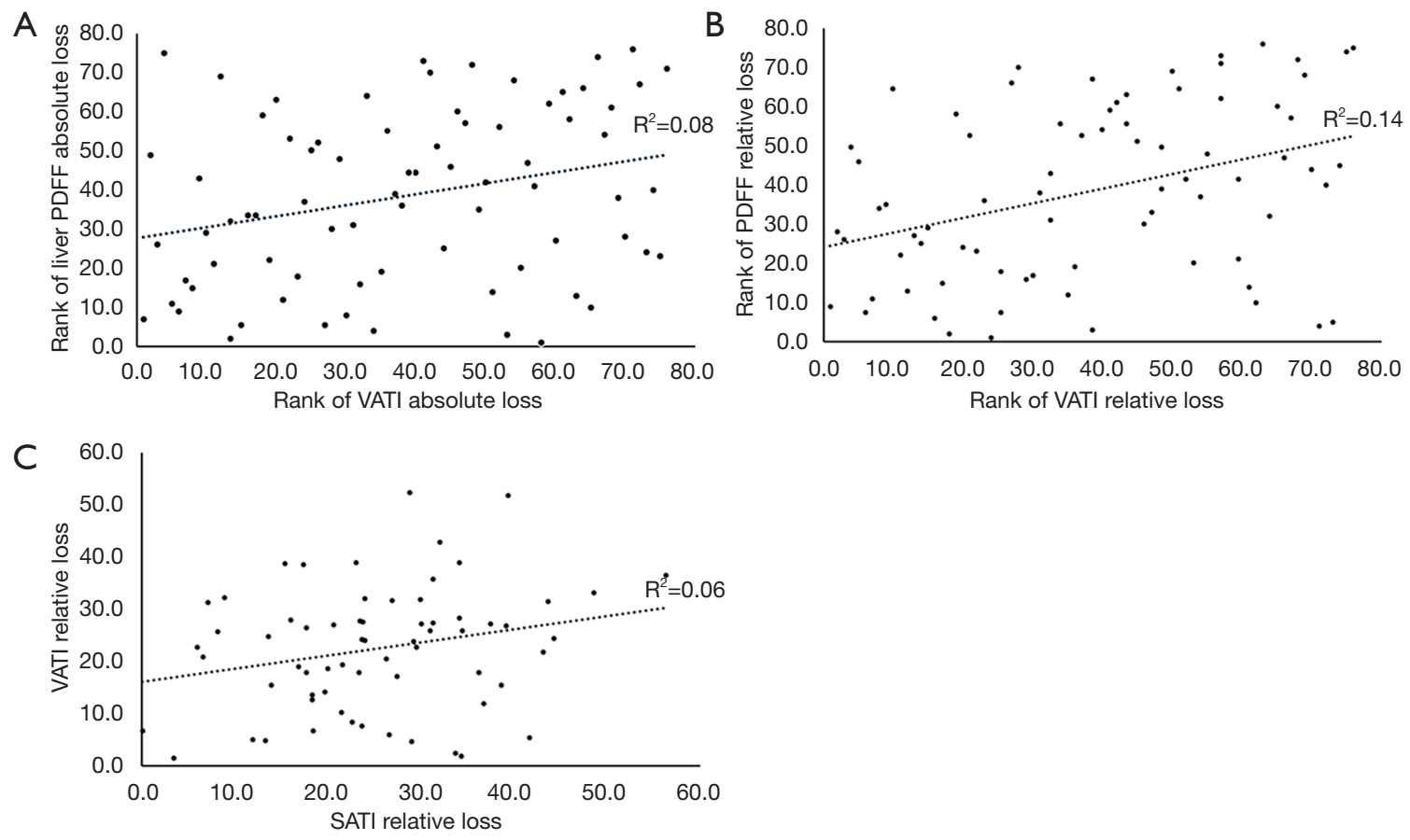

Figure 6 Linear plots showing the correlation among reductions in different types of abdominal fat. (A) The correlation between the absolute reduction in VATI and absolute reduction in liver PDFF was statistically significant $(\mathrm{r}=0.283, \mathrm{P}=0.013)$. (B) The correlation between the relative reduction in VATI and relative reduction in liver PDFF was statistically significant $(\mathrm{r}=0.372, \mathrm{P}=0.001)$. $(\mathrm{C}) \mathrm{The}$ correlation between the relative reduction in SATI and relative reduction in VATI was statistically significant $(\mathrm{r}=0.245$, $\mathrm{P}=0.049)$. PDFF, proton density fat fraction; SATI, subcutaneous adipose tissue index; VATI, visceral adipose tissue index.

and BMI changes in men. However, gender and different baseline VATI contributed to the difference between men's and women's absolute VATI reduction, as the preoperative VATI in men reached nearly 1.3 times that of women $\left(8.5 \times 10^{-3}\right.$ vs. $\left.6.5 \times 10^{-3}\right)$.

Additionally, our results showed that the females underwent significantly larger EWL after three months. Consequently, we could infer that those female patients would be more likely to reach the target weight loss. This conclusion differed from a previous study by Kenngott et al. (7), who found no identifiable difference in EWL between genders at three months and twelve months.

The correlation between absolute/relative reduction in VATI and absolute/relative reduction in liver PDFF was found to be statistically significant $(r=0.283, P=0.013 ; r=0.372$, $\mathrm{P}=0.001)$. According to the "portal hypothesis", increased lipolysis of visceral fat would lead to deposition of free fatty acids in the liver (21). However, we observed a reduction in visceral adiposity, with the decrease in fatty liver grade. With the changes of metabolism-related gene expression, the amount and composition of the diet, the actual metabolic status of postoperative patients is complex, while relevant studies have not been in-depth. Hence, there should be more attention to the mechanism.

In the present study, we demonstrated that a correlation existed between the absolute change in VATI and weight reduction and the absolute change in SATI + VATI and weight reduction. These findings suggest that the decrease in abdominal fat deposits, especially the loss in VATI, correlates with loss of body weight, which is supported by the finding that the relative reduction in VATI is associated with EWL/TWL.

Concerning the physiological and biochemical changes associated with obesity and an increase in the volume of adipose tissue, understanding the change in the fatty acid (FA) composition is also worthy of attention. Nemeth et al. $(22,23)$ proposed that chemical-shift-encoded MRI (CSEMRI), a non-invasive technique, could be used as an accurate measurement of FA, and the results were highly consistent and correlated with magnetic resonance spectroscopy (MRS) results. With this new protocol, they found changes in VAT FA composition after 31 days of overfeeding. The 

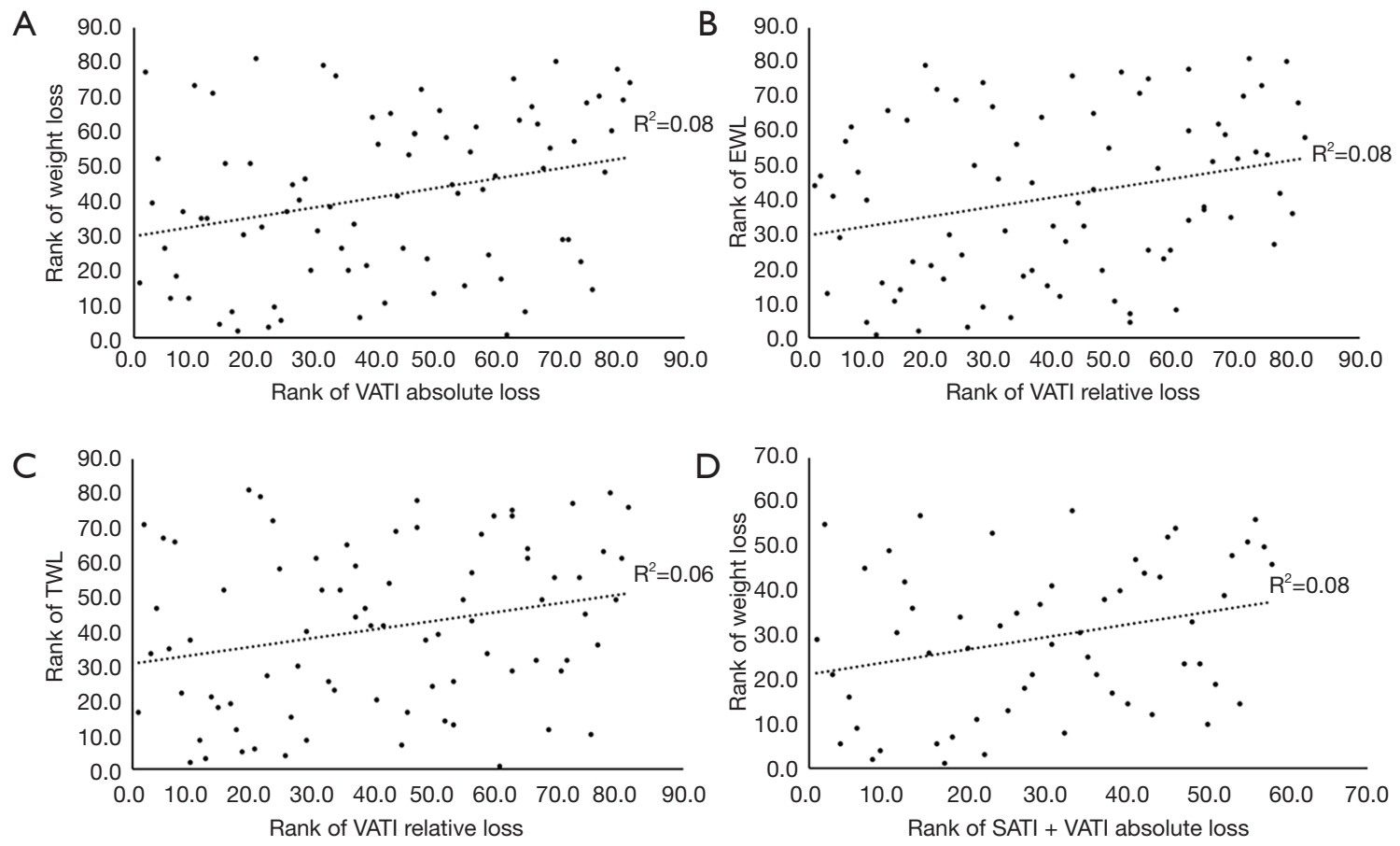

Figure 7 Linear plots showing the correlation between abdominal fat reduction and changes in weight-related parameters. (A) The absolute loss in VATI was correlated with weight loss $(\mathrm{r}=0.282, \mathrm{P}=0.011)$. (B) The relative loss in VATI was correlated with $\mathrm{EWL}$ ( $\mathrm{r}=0.274, \mathrm{P}=0.013$ ). (C) The relative loss in VATI was correlated with TWL $(\mathrm{r}=0.252, \mathrm{P}=0.022)$. (D) The absolute reduction in SATI + VATI was correlated with weight loss ( $\mathrm{r}=0.282, \mathrm{P}=0.032)$. SATI, subcutaneous adipose tissue index; VATI, visceral adipose tissue index; EWL, excess weight loss; TWL, total weight loss.

polyunsaturated fatty acid (PUFA) content decreased, and the monounsaturated fatty acid (MUFA) content increased compared with the baseline period (23). This finding suggested that the molecular composition of fat, as a significant marker of AT metabolism, could be accurately analyzed by CSE-MRI and applied in the longitudinal followup of patients undergoing bariatric and metabolic surgery.

\section{Methodological considerations}

To evaluate body tissue composition, a considerable number of researchers choose computed tomography (CT) (24-28). In Europe, North America, and parts of Asia, people who make an appointment for an MR examination will wait longer than those who require a CT examination, possibly for months $(29,30)$. This lag time will certainly reduce the compliance of patients with follow-up visits. In contrast to MRI, the cost of CT examination is lower, and the image collection method is relatively simple, so it is widely adopted. Pleasingly, our study was able to follow the actual clinical practice in China to conduct the pre- and postsurgery evaluations using MRI. A conventional abdominal magnetic resonance scan in China costs approximately $\$ 120$, while a CT scan of the abdomen costs approximately $\$ 80$. The extra $\$ 40$ cost is acceptable for patients. In addition, MR is superior to CT on the high contrast resolution of soft tissue, and as such, there may be incidental findings that can be managed without additional imaging such as CT, endoscopy, and ultrasound (18). The spending on medical imaging is greatly reduced, and the time duration before bariatric surgery is shortened because of the efficiencies of the MR process in China. Repeatable and comparable measurements on MR also facilitate the curative effect evaluation. Furthermore, MR, which is free of radiation exposure, is especially healthier among those patients requiring frequent follow-up visits. Considering the above advantages, clinicians in China tend to choose MRI for a more comprehensive evaluation of postoperative outcomes.

Although the feasibility of analyzing the body composition by MR examination has already been 
recognized (31-33), there are few reports on the use of upper abdominal MRI in such studies. Upper abdominal MRI has several advantages over whole-body MRI: short image acquisition time (15 $\mathrm{s}$ for the acquisition of LAVAFlex sequence and $17 \mathrm{~s}$ for IDEAL IQ sequence) and lower cost. The number of patients enrolled in our study was 91 , and these were exclusively patients receiving LSG surgery. In the future, we could conduct multiple postoperative follow-ups on thousands of patients found in the GC-MBD with obesity. We acknowledge that, when used with many patients, the systemic assessment approach is obviously not realistic. The high cost and time-consuming characteristics of whole-body MR also limit its clinical application (18).

In order to improve efficiency and reduce cost, we determined to evaluate abdominal fat change from the change measured within a single level. Whole-body or regional measurements of fat change are indeed the most precise method. Single-level evaluation of change is a new alternative approach that we are exploring. It reflects a decrease in abdominal fat content, thus to a certain extent, it meets the clinical needs for evaluation of postoperative fat reduction. Previous studies have taken a similar approach and provide support for the approach to our study $(18,34,35)$.

Nevertheless, researchers have yet to reach an agreement on the single standard slice (36-38) for the quantification of SAT/VAT. From numerous studies, we found those fat measurements at the axial level of L1-L2 intervertebral disc, while not the best, were strongly correlated with total fat volumes $(34,36,38,39)$. An unpublished meta-analysis by our group showed that fat measurements at single axial slices were highly correlated with total body fat volumes at all slices between L1 and $\mathrm{S} 1\left(\mathrm{r}^{\mathrm{SAT}}: 0.90-0.97 ; \mathrm{r}^{\mathrm{VAT}}: 0.84-0.98\right)$. Further, the results at the L1-L2 level were only slightly different from the best results at the L2-L3 level $\left(\mathrm{r}^{\mathrm{SAT}} 0.95\right.$ vs. $0.97 ; \mathrm{r}^{\mathrm{VAT}} 0.96$ vs. 0.98).

As one of China's highest-volume bariatric and metabolic surgery centers, upper abdominal MRI is the routine examination used here for preoperative and postoperative evaluation. In most patients, the upper abdominal MRI includes the L1-L2 level (93.1\%) and is less likely to include the L2-L3 level and below (43.7\%) (18). Therefore, under the current clinical background, the level of L1-L2 was considered to be the most appropriate and accessible site for evaluating abdominal fat volumes (18).

\section{Limitations}

The unequal gender distribution is a limitation of this study. We were performing a retrospective study with a continuous enrollment approach within a specified period. In our center, most patients receiving bariatric and metabolic surgery were females $(73.3 \%)$, while males only accounted for $26.7 \%$. The characteristics of patient distribution included in the study were consistent with the clinical background. The method of enrolling subjects needs to be further improved to achieve a basic balance between genders. The lack of analysis on fatty acid composition is also a limitation of our study. We did not acquire magnetic resonance spectrum (MRS), which is used for the quantification of chemical composition and content of human tissue metabolites, nor employ the CSE-MRI.

Obesity status is closely linked with an increasing prevalence of diverse metabolic syndromes such as hyperlipidemia and hyperglycemia (2). Furthermore, progressive and irreversible metabolic abnormalities may contribute to some chronic diseases, including coronary atherosclerotic heart disease (CAHD), obstructive sleep apnea-hypopnea syndrome (OSAHS), and polycystic ovary syndrome (PCOS) $(2,40,41)$. However, how the weight loss or fat reduction would lead to improvement of laboratory measurements and reduced prevalence of those clinical comorbidities is not included in this study. This is because the available data are of limited value in interpreting metabolic outcomes. Individual body compartments do not stand alone; rather, they have to be seen in the context of body function.

\section{Conclusions}

Upper abdominal MRI was used in this study to analyze and compare the changes in abdominal fat deposits about three months after bariatric surgery in Chinese patients. We observed the greatest absolute loss in SAT and the greatest relative change in liver PDFF. Weight loss, BMI loss and absolute/relative change in VAT were found to be more evident in males than in females. For severely obese patients, an upper abdominal MR examination is recommended for the assessment of body tissue composition and how it changes after bariatric surgery.

\section{Acknowledgments}

The authors would like to thank all the study investigators, staff, clinicians, nurses and technicians for dedicating their time and skills to the completion of this study. We would like to thank these researchers: Peirong Tian, Shibo Bian, 
Meng Zhang, Di Cao, and Jia Liu.

Funding: This work was supported by Capital's Funds for Health Improvement and Research (No. 2020 1-2021); Beijing Scholars Program [No. (2015) 160]; Beijing Hospitals Authority Youth Programme (QML20180103); China Postdoctoral Science Foundation (No. 2019M660717) and Beijing Postdoctoral Research Foundation (No. 2020-Z2-023).

\section{Footnote}

Conflicts of Interest: All authors have completed the ICMJE uniform disclosure form (available at https://dx.doi. org/10.21037/qims-20-1380). The authors have no conflicts of interest to declare.

Ethical Statement: The authors are accountable for all aspects of the work and ensuring that questions related to the accuracy or integrity of any part of the work are appropriately investigated and resolved. The study was conducted in accordance with the Declaration of Helsinki (as revised in 2013). The study was approved by the Medical Ethics Committee of Beijing Friendship Hospital (NO. 2017-P2-131-02) and individual consent for this retrospective analysis was waived.

Open Access Statement: This is an Open Access article distributed in accordance with the Creative Commons Attribution-NonCommercial-NoDerivs 4.0 International License (CC BY-NC-ND 4.0), which permits the noncommercial replication and distribution of the article with the strict proviso that no changes or edits are made and the original work is properly cited (including links to both the formal publication through the relevant DOI and the license). See: https://creativecommons.org/licenses/by-nc-nd/4.0/.

\section{References}

1. Finkelstein EA, Sherry B, Trogdon JG, Thompson H, Pan L, Khavjou OA, Dietz W. Obesity and severe obesity forecasts through 2030. Am J Prev Med 2012;42:563-70.

2. Kissler HJ, Settmacher U. Bariatric surgery to treat obesity. Semin Nephrol 2013;33:75-89.

3. Brown RE, Kuk JL, Lee S. Measurement site influences abdominal subcutaneous and visceral adipose tissue in obese adolescents before and after exercise. Pediatr Obes 2015;10:98-104.

4. Lee S, Deldin AR, White D, Kim Y, Libman I, Rivera-
Vega M, Kuk JL, Sandoval S, Boesch C, Arslanian S. Aerobic exercise but not resistance exercise reduces intrahepatic lipid content and visceral fat and improves insulin sensitivity in obese adolescent girls: a randomized controlled trial. Am J Physiol Endocrinol Metab 2013;305:E1222-9.

5. Diab AF, Abdurasul EM, Diab FH. The Effect of Age, Gender, and Baseline BMI on Weight Loss Outcomes in Obese Patients Undergoing Intragastric Balloon Therapy. Obes Surg 2019;29:3542-6.

6. Kröner Florit PT, Corral Hurtado JE, Wijarnpreecha K, Elli EF, Lukens FJ. Bariatric Surgery, Clinical Outcomes, and Healthcare Burden in Hispanics in the USA. Obes Surg 2019;29:3646-52.

7. Kenngott HG, Nickel F, Wise PA, Wagner F, Billeter AT, Nattenmuller J, Nabers D, Maier-Hein K, Kauczor HU, Fischer L, Muller-Stich BP. Weight Loss and Changes in Adipose Tissue and Skeletal Muscle Volume after Laparoscopic Sleeve Gastrectomy and Roux-en-Y Gastric Bypass: a Prospective Study with 12-Month Follow-Up. Obes Surg 2019;29:4018-28.

8. Tang L, Zhang F, Tong N. The association of visceral adipose tissue and subcutaneous adipose tissue with metabolic risk factors in a large population of Chinese adults. Clin Endocrinol (Oxf) 2016;85:46-53.

9. Celio AC, Pories WJ. A History of Bariatric Surgery: The Maturation of a Medical Discipline. Surg Clin North Am 2016;96:655-67.

10. Umemura A, Lee WJ, Sasaki A, Wakabayashi G. History and current status of bariatric and metabolic surgeries in East Asia. Asian J Endosc Surg 2015;8:268-74.

11. Porter SA, Massaro JM, Hoffmann U, Vasan RS, O'Donnel CJ, Fox CS. Abdominal subcutaneous adipose tissue: a protective fat depot? Diabetes Care 2009;32:1068-75.

12. Matsha TE, Ismail S, Speelman A, Hon GM, Davids S, Erasmus RT, Kengne AP. Visceral and subcutaneous adipose tissue association with metabolic syndrome and its components in a South African population. Clin Nutr ESPEN 2019;32:76-81.

13. Hall YN, Xu P, Chertow GM. Relationship of Body Size and Mortality among Us Asians and Pacific Islanders on Dialysis. Ethn Dis 2011;21:40-6.

14. Kleine CE, Moradi H, Streja E, Kalantar-Zadeh K. Racial and Ethnic Disparities in the Obesity Paradox. Am J Kidney Dis 2018;72:S26-32.

15. WHO Expert Consultation. Appropriate body-mass index for Asian populations and its implications for policy and intervention strategies. Lancet 2004;363:157-63. 
16. Li M, Cao D, Liu Y, Jin L, Zeng N, Wang L, Zhao K, Lv $\mathrm{H}$, Zhang $\mathrm{M}$, Zhang $\mathrm{P}$, Yang $\mathrm{Z}$, Zhang $\mathrm{Z}$. Alterations in the Liver Fat Fraction Features Examined by Magnetic Resonance Imaging Following Bariatric Surgery: a Self-Controlled Observational Study. Obes Surg 2020;30:1917-28.

17. Idilman IS, Aniktar H, Idilman R, Kabacam G, Savas B, Elhan A, Celik A, Bahar K, Karcaaltincaba M. Hepatic steatosis: quantification by proton density fat fraction with MR imaging versus liver biopsy. Radiology 2013;267:767-75.

18. Lv H, Li MY, Liu Y, Zhao L, Sun J, Cao D, Zeng N, Liu J, Liu YW, Bian SB, Zhang P, Yang ZH, Zhang ZT, Wang ZC. The Clinical Value and Appropriateness Criteria of Upper Abdominal Magnetic Resonance Examinations in Patients Before and After Bariatric Surgery: a Study of 837 Images. Obes Surg 2020;30:3784-91.

19. VanItallie TB, Yang MU, Heymsfield SB, Funk RC, Boileau RA. Height-normalized indices of the body's fatfree mass and fat mass: potentially useful indicators of nutritional status. Am J Clin Nutr 1990;52:953-9.

20. Engin A. The Definition and Prevalence of Obesity and Metabolic Syndrome. Adv Exp Med Biol 2017;960:1-17.

21. Kabir M, Catalano KJ, Ananthnarayan S, Kim SP, Van Citters GW, Dea MK, Bergman RN. Molecular evidence supporting the portal theory: a causative link between visceral adiposity and hepatic insulin resistance. Am J Physiol Endocrinol Metab 2005;288:E454-61.

22. Nemeth A, Segrestin B, Leporq B, Coum A, Gambarota G, Seyssel K, Laville M, Beuf O, Ratiney H. Comparison of MRI-derived vs. traditional estimations of fatty acid composition from MR spectroscopy signals. NMR Biomed 2018;31:e3991.

23. Nemeth A, Segrestin B, Leporq B, Seyssel K, Faraz K, Sauvinet V, Disse E, Valette PJ, Laville M, Ratiney H, Beuf O. 3D Chemical Shift-Encoded MRI for Volume and Composition Quantification of Abdominal Adipose Tissue During an Overfeeding Protocol in Healthy Volunteers. J Magn Reson Imaging 2019;49:1587-99.

24. Chowdhury B, Kvist H, Andersson B, Bjorntorp P, Sjostrom L. CT-determined changes in adipose tissue distribution during a small weight reduction in obese males. Int J Obes Relat Metab Disord 1993;17:685-91.

25. Irlbeck T, Massaro JM, Bamberg F, O'Donnell CJ, Hoffmann U, Fox CS. Association between single-slice measurements of visceral and abdominal subcutaneous adipose tissue with volumetric measurements: the Framingham Heart Study. Int J Obes (Lond)
2010;34:781-7.

26. Kaess BM, Pedley A, Massaro JM, Murabito J, Hoffmann $\mathrm{U}$, Fox CS. The ratio of visceral to subcutaneous fat, a metric of body fat distribution, is a unique correlate of cardiometabolic risk. Diabetologia 2012;55:2622-30.

27. Fox CS, Massaro JM, Hoffmann U, Pou KM, MaurovichHorvat P, Liu CY, Vasan RS, Murabito JM, Meigs JB, Cupples LA, D'Agostino RB Sr, O'Donnell CJ. Abdominal visceral and subcutaneous adipose tissue compartments: association with metabolic risk factors in the Framingham Heart Study. Circulation 2007;116:39-48.

28. Rosito GA, Massaro JM, Hoffmann U, Ruberg FL, Mahabadi AA, Vasan RS, O'Donnell CJ, Fox CS. Pericardial fat, visceral abdominal fat, cardiovascular disease risk factors, and vascular calcification in a community-based sample: the Framingham Heart Study. Circulation 2008;117:605-13.

29. Bor DS, Sharpe RE, Bode EK, Hunt K, Gozansky WS. Increasing Patient Access to MRI Examinations in an Integrated Multispecialty Practice. Radiographics 2021;41:E1-8.

30. Tokur S, Lederle K, Terris DD, Jarczok MN, Bender S, Schoenberg SO, Weisser G. Process analysis to reduce MRI access time at a German University Hospital. Int J Qual Health Care 2012;24:95-9.

31. Baum T, Cordes C, Dieckmeyer M, Ruschke S, Franz D, Hauner H, Kirschke JS, Karampinos DC. MR-based assessment of body fat distribution and characteristics. Eur J Radiol 2016;85:1512-8.

32. Ludescher B, Machann J, Eschweiler GW, Vanhöfen S, Maenz C, Thamer C, Claussen CD, Schick F. Correlation of Fat Distribution in Whole Body MRI With Generally Used Anthropometric Data. Invest Radiol 2009;44:712-9.

33. Hui SCN, Wong SKH, Ai Q, Yeung DKW, Ng EKW, Chu WCW. Observed changes in brown, white, hepatic and pancreatic fat after bariatric surgery: Evaluation with MRI. Eur Radiol 2019;29:849-56.

34. Abate N, Garg A, Coleman R, Grundy SM, Peshock RM. Prediction of total subcutaneous abdominal, intraperitoneal, and retroperitoneal adipose tissue masses in men by a single axial magnetic resonance imaging slice. Am J Clin Nutr 1997;65:403-8.

35. Grønberg BH, Sjoblom B, Wentzel-Larsen T, Baracos VE, Hjermstad MJ, Aass N, Bremnes RM, Flotten O, Bye A, Jordhoy M. A comparison of CT based measures of skeletal muscle mass and density from the Th4 and L3 levels in patients with advanced non-small-cell lung cancer. Eur J Clin Nutr 2019;73:1069-76. 
36. Schweitzer L, Geisler C, Pourhassan M, Braun W, Glüer CC, Bosy-Westphal A, Müller MJ. What is the best reference site for a single MRI slice to assess whole-body skeletal muscle and adipose tissue volumes in healthy adults? Am J Clin Nutr 2015;102:58-65.

37. Lee S, Janssen I, Ross R. Interindividual variation in abdominal subcutaneous and visceral adipose tissue: influence of measurement site. J Appl Physiol (1985) 2004;97:948-54.

38. Kuk JL, Church TS, Blair SN, Ross R. Measurement site and the association between visceral and abdominal subcutaneous adipose tissue with metabolic risk in women. Obesity 2010;18:1336-40.

Cite this article as: Sun J, Lv H, Li M, Zhao L, Liu Y, Zeng N, Wei X, Chen Q, Ren P, Liu Y, Zhang P, Yang Z, Zhang Z, Wang Z. How much abdominal fat do obese patients lose short term after laparoscopic sleeve gastrectomy? A quantitative study evaluated with MRI. Quant Imaging Med Surg 2021;11(11):4569-4582. doi: 10.21037/qims-20-1380
39. Kuk JL, Church TS, Blair SN, Ross R. Does measurement site for visceral and abdominal subcutaneous adipose tissue alter associations with the metabolic syndrome? Diabetes Care 2006;29:679-84.

40. Guh DP, Zhang W, Bansback N, Amarsi Z, Birmingham $\mathrm{CL}$, Anis AH. The incidence of co-morbidities related to obesity and overweight: a systematic review and metaanalysis. BMC Public Health 2009;9:88.

41. Li M, Liu Y, Jin L, Zeng N, Wang L, Zhao K, Lv H, Zhang M, Xu W, Zhang P, Zhang Z. Metabolic Features of Individuals with Obesity Referred for Bariatric and Metabolic Surgery: a Cohort Study. Obes Surg 2019;29:3966-77. 